\title{
POLÍTICAS PÚBLICAS E CAPITAL HUMANO PARA O DESENVOLVIMENTO LOCAL DA PESCA ARTESANAL
}

\author{
J. H. M. FERRAZ* e F. N. O. ARRAIS \\ Instituto Federal de Educação, Ciência e Tecnologia do Rio Grande do Norte - IFRN \\ joao.ferraz@ifrn.edu.br ${ }^{*}$
}

Artigo submetido em maio/2013 e aceito em outubro/2014

DOI: $10.15628 /$ holos.2014.1452

\section{RESUMO}

Este trabalho identifica e analisa as políticas públicas de extensão pesqueira para o desenvolvimento local do Município de Porto de Pedras, Alagoas, entre 2003 e 2009, por meio dos projetos estabelecidos pelo governo. Especificamente, se analisa o capital humano da colônia de pescadores Z-25, frente aos projetos tecnológicos ligados à pesca artesanal. A metodologia utilizada neste trabalho foi a identificação das políticas públicas para o desenvolvimento da pesca artesanal, além de aplicação de questionários semiestruturados com os gestores e técnicos do MPA e da SEAGRI/AL, e pescadores da colônia. Tais entrevistas tiveram a finalidade de analisar o capital humano e de compreender como essas políticas de inovação tecnológicas são incorporadas na pesca. Com os dados identificou-se uma carência de políticas públicas que associem o fomento do capital humano da pesca artesanal com o desenvolvimento local.

PALAVRAS-CHAVE: Pesca Artesanal, Extensão Pesqueira, Desenvolvimento Local, Capital humano.

\section{PUBLIC POLICIES AND HUMAN CAPITAL FOR LOCAL DEVELOPMENT OF TRADITIONAL FISHERIES}

\begin{abstract}
This study aimed to identify and analyze public policies for Fishing Extension for local development in the city Porto de Pedras, Alagoas, from 2003 to 2009, through the projects established by governmental organizations such as Fishing and Aquaculture Ministry (MPA) and Agriculture and Agrarian Development Department of the State of Alagoas (SEAGRI/AL). We intended to analyze the human capital of the fishing community Z-25, from Porto de Pedras, within technological projects related to the fishing offered by public policies. We based this study on the question: how has the fishing human capital been considered and contemplated by the government to support local development? The methodological
\end{abstract}

approach to the development of this work was to initially identify the public policies for the development of fisheries in Porto de Pedras, using electronic site and bibliographic material. Then, interviews were conducted with MPA and SEAGRI/AL technicians, and fishermen associated with the fishing colony Z-25 who took part in projects developed by governmental organizations in Porto de Pedras. From the analysis of the data, we concluded that the implemented projects had a little contribution to the process of human capital training, which provides the local development through the fishing activity.

KEYWORDS: Traditional Fisheries, Fishing Extension, Local Development, Human Capital. 


\section{INTRODUÇÃO}

O objetivo deste trabalho é identificar e analisar as políticas públicas de extensão pesqueira para o desenvolvimento local no Município de Porto de Pedras, Alagoas, entre 2003 e 2009, por meio dos projetos estabelecidos pelas organizações governamentais. Especificamente, o que se pretende é analisar o capital humano da Colônia de Pescadores Z-25, de Porto de Pedras, frente aos projetos tecnológicos ligados à pesca artesanal propostos pelas políticas públicas.

As políticas de Extensão Pesqueira no Brasil surgem a partir de 1968 com o objetivo de desenvolver as atividades de pesca. $\mathrm{O}$ argumento principal dessa iniciativa era a "imensidão da costa nacional, a sua piscosidade de suas águas e o desamparo socioeconômico das comunidades pesqueiras artesanais" (Callou, 1986, p. 285-300). Essas políticas foram promovidas pela Superintendência do Desenvolvimento da Pesca (SUDEPE), autarquia criada pela lei № 10 de 1962, vinculada ao Ministério da Agricultura, com o objetivo de desenvolver a pesca nacional (Brasil, 1962).

Ao longo da década de 1970, a Extensão Pesqueira teve como ação principal apoiar a modernização do setor pesqueiro nacional (Callou e Tauk Santos, 2003). Para isso, entre outras estratégias, implementou, a partir de 1974, o Plano de Assistência à Pesca Artesanal (PESCART), com o apoio do Ministério da Agricultura, do Banco Nacional de Crédito (BNC), do Instituto Nacional de Colonização e Reforma Agrária (INCRA) e da SUDEPE. Entre os objetivos principais do PESCART estavam "modernizar a atividade pesqueira artesanal no intuito de promover inserção dos produtos da pesca no mercado a fim de facilitar e possibilitar que os pescadores artesanais vendessem seus produtos em melhores condições de competitividade [...]" (Carvalho, 2007, p. 25). Para Callou (1995), o objetivo do PESCART era modificar as técnicas e as tecnologias de pesca utilizadas pelos pescadores artesanais através de políticas de desenvolvimento.

Essas estratégias de ação tecnológica para os pescadores artesanais, no entanto, foram consideradas insatisfatórias já que essa política resultou em impactos socioambientais e econômicos negativos (Diegues, 1983).

Para Cunha (2009), o PESCART, por ter se voltado para difusão tecnológica, e não para o desenvolvimento dos pescadores artesanais, não conseguiu promover o desenvolvimento social desses trabalhadores.

Nesse sentido, Callou (1994) também constatou poucos resultados a partir daquelas intervenções, isto é, daquelas políticas públicas para o desenvolvimento do setor pesqueiro no país. Callou e Tauk Santos (2001) corroboraram afirmando que em duas décadas a práxis extensionista pesqueira, pautada na modernização tecnológica, não atingiu os objetivos propostos para o desenvolvimento do setor pesqueiro artesanal. Aspecto igualmente observado por Carvalho (2007).

Para a consolidação dessa prática de difusão tecnológica, Callou e Tauk Santos (2003) afirmam que a estratégia estava baseada numa comunicação persuasiva, na qual as comunidades "alvo" deveriam ser convencidas a adotarem os pacotes tecnológicos. À época, os gestores públicos e extensionistas pesqueiros acreditavam que ao aplicar esse modelo de comunicação voltada à difusão tecnológica nas comunidades de pescadores possibilitaria a utilização de novos processos produtivos que resultariam em uma maior produção pesqueira e uma melhoria de 
renda, proporcionando, para esse grupo de trabalhadores, uma vida confortável (Callou e Tauk Santos, 2003).

Diegues (1983) afirma que os resultados dessa política não foram animadores, tendo em vista os impactos socioambientais e econômicos negativos. O autor ainda avalia que foi a partir da década de 1960 que se verificou uma maior intensidade de poluição aos ambientes aquáticos, um decréscimo da produção gerada pelas unidades familiares dos pescadores artesanais, uma ênfase dada à pesca industrial com incentivos fiscais, que resultaram na criação de diversas empresas de pesca, que sobrepescaram os estoques marinhos e concorreram deslealmente com os pescadores artesanais (Diegues, 1995a).

Além disso, outros pesquisadores também criticaram essas políticas de extensão pesqueira por historicamente não contemplar as demandas locais, já que negavam as culturas tradicionais na pesca, considerando-as "atrasadas". Assim, não se levou em conta, as habilidades e os conhecimentos endógenos e peculiares de cada comunidade. Nesse sentido, Tauk-Santos e Callou (1995) assim se referem:

fato é que pouco se conhecia (e pouco se considerava) os aspectos de ordem cultural das populações envolvidas com a pesca artesanal. A maneira como os pescadores catalogavam seu cotidiano, suas formas de aprendizagem, de conhecimento e difusão desse conhecimento no contexto familiar e social pesqueiro, não era considerada como variável fundamental na elaboração dos projetos governamentais de desenvolvimento. Esse fator, ao contrário, era percebido como empecilho ao desenvolvimento pretendido: a "ignorância", a "preguiça", o "despreparo técnico" e o "pessimismo" do pescador eram termos incorporados ao vocabulário extensionista (Tauk Santos e Callou, 1995, p. 43).

Essa concepção estatal também foi rebatida por Diegues (1995b), quando relata a importância desse conhecimento tradicional, afirmando que os oceanos deveriam ser compreendidos não só por sua realidade físico-biológica, mas também por sua realidade humana e seus símbolos. Especificamente sobre as comunidades pesqueiras, o autor afirma:

essas populações têm uma percepção complexa do meio-marinho e seus fenômenos naturais. De um lado, há um vasto conhecimento empírico adquirido pela observação continuada dos fenômenos físicos e biológicos (ventos, marés, reprodução dos cardumes de peixes) que hoje começa a ser explorado pela chamada etnociência marítima. De outro lado as explicações para tais fenômenos também passam pela representação simbólica e pelo imaginário dos povos do mar (Diegues, 1995b, p. 5).

Quando se percorre o itinerário histórico a partir da promulgação da Lei no 10 de 1962, que criou a Superintendência do Desenvolvimento da Pesca, passando pelo surgimento do Plano de Assistência à Pesca Artesanal, assim como pela promulgação da Lei 7.735, que extinguiu a SUDEPE para criar o Instituto Brasileiro do Meio Ambiente e dos Recursos Naturais Renováveis (IBAMA), observa-se uma intervenção no universo social e econômico da pesca artesanal pelo poder público, através da imposição de novas tecnologias e da desvalorização do conhecimento e das tecnologias endógenas dos contextos sociais dos pescadores artesanais.

Para Vasconcelos (2009), esse quadro se agrava com a extinção da SUDEPE. Diz ele que o setor Pesqueiro fragilizou-se ainda mais, já que houve um hiato de mais de uma década, até o 
surgimento, em 2003, da Secretaria Especial de Aquicultura e Pesca da Presidência da República (Seap/PR), hoje Ministério da Pesca e Aquicultura (MPA).

Nessa perspectiva, a Secretaria Especial de Aquicultura e Pesca concebe seu Projeto Político Estrutural para a Pesca, que se preocupa também em reparar a dívida histórica da Nação para com os trabalhadores do setor, especificamente para com os pescadores artesanais. Nesse sentido, também apresenta seu Plano Nacional de Assistência Técnica e Extensão Pesqueira e Aquícola (ATEPA). Este plano, de abrangência nacional, busca assegurar e consolidar uma política de Assistência Técnica e Extensão Pesqueira e Aquícola que promova o desenvolvimento sustentável da aquicultura familiar e da pesca artesanal. Essas diretrizes da Seap/PR (consolidação de uma política de Estado para a pesca, inclusão social, territorialidade, sustentabilidade ambiental) encontram consistência e conformidade nos objetivos da própria ATEPA, que assim informa em seu objetivo geral:

Promover e apoiar iniciativas de desenvolvimento local sustentável, que envolvam atividades pesqueiras e aquícolas ou a elas relacionadas, considerando a família do pescador artesanal, o aquicultor familiar e suas organizações, visando à inclusão social e a melhoria da qualidade de vida das comunidades pesqueiras e aquícolas, adotando os princípios da conservação, gestão ambiental e da aquicultura e pesca responsáveis (Brasil, 2007, p. 3).

Essa noção de desenvolvimento local abre possibilidades para o envolvimento dos contextos populares da pesca participar das políticas públicas do setor pesqueiro. Isso também fica explícito no Plano Nacional de Assistência Técnica e Extensão Rural (PNATER), como se observa na citação a seguir:

[...] abre o caminho para a participação e o controle social sobre as políticas públicas, de modo que se estabeleçam possibilidades concretas para que o aparato estatal e os serviços públicos em geral fiquem à disposição da população particularmente daqueles segmentos até então alijados do processo de desenvolvimento (Brasil, 2004, p. 3).

Dessa forma, a versão contemporânea da extensão pesqueira em prol do desenvolvimento local poderá contribuir substancialmente para a concepção e implementação das políticas públicas em comunidades pesqueiras desfavorecidas.

Sobre o desenvolvimento local, Jesus (2003) afirma que este deve ser:

um processo que mobiliza pessoas e instituições buscando a transformação da economia e da sociedade locais, criando oportunidades de trabalho e de renda, superando dificuldades para favorecer a melhoria das condições de vida da população local. [...] trata-se de um esforço localizado e concertado (Jesus, 2003, p. 72).

Jara (2001) entende que para instaurar os processos de desenvolvimento local é de suma importância que se estimule o capital social e humano, através da implementação de políticas norteadas pela equidade e satisfação das necessidades humanas, pelo respeito aos recursos naturais, e que permitam o empoderamento dos atores sociais. 
Tendo em vista que o capital humano sob o viés das habilidades e conhecimentos empíricos não foi considerado historicamente pelas políticas públicas de desenvolvimento da pesca artesanal, pareceu-nos ser relevante como foco de análise desta pesquisa esse tipo de capital na elaboração e implementação das políticas públicas atuais de extensão pesqueira voltadas para o desenvolvimento local.

Jara (2001, p. 102) afirma que "o investimento em capital humano, em 'agentes de desenvolvimento' - mulheres e homens educados, motivados e com habilidades para conduzir processos de mudanças, representa uma estratégia indispensável para alcançar uma sociedade sustentável".

Em 2009, com a promulgação da lei 11.958, que transformou a Seap/PR em Ministério da Pesca e Aquicultura (MPA), o Governo Federal manteve as diretrizes políticas estabelecidas pela Seap/PR. Isto significa dizer que, de um modo geral, ou no nível do discurso, as instituições relacionadas à atividade da extensão pesqueira entendem ser fundamental o diálogo com a sociedade civil, recebendo suas demandas para um tratamento político institucional como resposta.

Frente a esses aspectos ligados às intervenções históricas de políticas públicas para o desenvolvimento do setor pesqueiro artesanal do Brasil e a atual perspectiva do desenvolvimento local na Extensão Pesqueira, é de se perguntar de que forma o capital humano da pesca artesanal tem sido valorizado e contemplado pelo poder público na atualidade para apoiar o desenvolvimento local das comunidades pesqueiras tradicionais.

Essa preocupação com o desenrolar dos projetos governamentais no âmbito do setor pesqueiro artesanal vem ao encontro dos objetivos do Projeto Casadinho (2006), voltados a mapear as políticas públicas desenvolvidas em alguns Estados do Nordeste do Brasil. O Estado de Alagoas, por possuir um grande potencial pesqueiro, tendo em vista suas dezessete lagoas, dentre elas, o complexo Lagunar Mundaú- Manguaba, além do Rio São Francisco, do litoral e das áreas estuarinas, assumiu relevância nesta pesquisa.

No Estado de Alagoas, foi escolhido o município de Porto de Pedras como unidade de análise desta pesquisa por ser um município que desenvolve projetos governamentais, em parceira com Ministério da Pesca e Aquicultura (MPA) e com a Secretaria de Agricultura e do Desenvolvimento Agrário do Estado de Alagoas (SEAGRI). Ao lado disso, observou-se na pesquisa exploratória realizada que a Colônia de Pesca Z-25, de Porto de Pedras, conta com a participação efetiva de seus cinquenta e sete associados.

A estratégia metodológica utilizada para o desenvolvimento deste trabalho foi de identificar inicialmente as políticas públicas para o desenvolvimento da pesca artesanal em Porto de Pedras, entre 2003 e 2009.

Em seguida, realizaram-se entrevistas com os três técnicos do Ministério da Pesca e Aquicultura (MPA), com o Diretor de Políticas Públicas para a Pesca da Secretaria de Agricultura e do Desenvolvimento Agrário do Estado de Alagoas (SEAGRI-AL), com o presidente da colônia de pesca de Porto de Pedras, além de nove pescadores associados à Z-25, selecionados aleatoriamente, os quais participaram ou participam de projetos sobre pesca artesanal, desenvolvidos por organizações governamentais. Tais entrevistas tiveram a finalidade de subsidiar um escopo de dados empíricos que auxiliem a análise do capital humano durante a execução de 
projetos na localidade e de como essas políticas de inovação tecnológicas são incorporadas ao cotidiano desses pescadores.

\section{POLÍTICAS PÚBLICAS DE EXTENSÃO PESQUEIRA E CAPITAL HUMANO PARA 0 DESENVOLVIMENTO LOCAL DA PESCA ARTESANAL}

Especificamente, neste trabalho, para identificar e analisar as políticas públicas de Extensão Pesqueira buscou-se delimitar a natureza, o conteúdo temático e seu segmento, isto é, a abrangência dos beneficiados dessas políticas públicas, conforme defende Teixeira (2002), e que nessa pesquisa são os pescadores artesanais.

Em seus estudos, Mattos e Drummond (2005) concluem que, historicamente, as políticas públicas não abrangeram a perspectiva da participação da sociedade civil na discussão, formulação e execução das políticas públicas. Essa exclusão também foi observada por Callou (1986), quando analisou as políticas públicas direcionadas às comunidades pesqueiras, e afirmou que aquelas políticas foram realizadas verticalmente, sem a participação dos beneficiários, os pescadores artesanais.

Teixeira (1997) afirma que ao passo da crise do aparelho de Estado os movimentos sociais começaram a surgir como novos atores sociais e políticos autônomos, que buscavam agir coletivamente a fim de conquistar suas aspirações e necessidades, as quais, não eram contempladas pelo poder público.

Nesse sentido, as comunidades de pescadores artesanais tiveram no Conselho Pastoral dos Pescadores (CPP) uma entidade aliada que fomentou a organização desse segmento socioeconômico.

Assim, através dessa parceria entre a CPP e os pescadores, criou-se o movimento de pescadores cristãos, denominado de "O Leme", que se propunha a buscar a "valorização da pessoa humana e a conscientização dos pescadores para solucionar parte de seus problemas" (Siry, 2003, p. 32).

Entretanto, Tauk Santos (2000) afirma que o modelo difusionista não havia sido abandonado e que na verdade o Estado buscou ajustar seu discurso à democratização que permeava o país na década de 1980.

Foi nesse cenário de abertura política no país, no qual as agências governamentais e ONGs incorporaram a pedagogia da participação, que se franqueou a "concertação".

Todavia, Santos e Spenillo (1997, p. 114) afirmam que essa concertação em parceria é complexa, pois "deixa-se de trabalhar apenas dentro de uma esfera de iguais, como outrora no âmbito governamental ou no âmbito dos movimentos sociais, ou ainda no setor da empresa privada, para trabalhar com diferentes".

Assim, como Cunha (2009), entendemos também que as políticas públicas devem ser elaboradas e implementadas a partir do modelo de concertação dos atores locais envolvidos, pois, mesmo que nesse espaço de complexidade surjam conflitos por opiniões divergentes, também é nesse espaço que surgem soluções para os problemas locais. 
Em suma, todo esse processo de participação política e social dos atores sociais proporciona como resultante o emponderamento dessa população e o fortalecimento do capital humano, tornando-os:

capazes de intervir na escolha, na formulação, na implementação, no controle das políticas governamentais e em atitudes que combinam a defesa e a criação de direitos com propostas socioeconômicas no contexto de mudanças tecnológicas e mercados competitivos (Jara, 2001, p. 100).

Franco (2000, apud Saraiva, 2000) enfatiza que o desenvolvimento, de fato, só é atingido quando se contempla os aspectos humano, social e sustentável.

Jara (2001) defende que o Estado deve fomentar o capital humano através do fortalecimento da democracia e do emponderamento dos atores sociais, satisfazendo paralelamente também as necessidades do homem, da natureza e da economia.

Assim, procuramos refletir neste estudo se o capital humano que exerce a pesca artesanal no município de Porto de Pedras é valorizado, fortalecido e como este tem sido contemplado pelas políticas públicas para o desenvolvimento local.

Nesses termos, Jara (2001) afirma também que é a partir desse empowerment, que surge a democratização da própria política de forma que esta esteja com sua finalidade voltada para os interesses dos cidadãos, isto é, quando estes propõem alternativas para os problemas por eles identificados.

Entendemos, neste trabalho, que tal conceito também é uma ferramenta para operacionalizar as organizações públicas, privadas e entidades de classe, tornando-as mais eficientes na elaboração das políticas públicas.

É, portanto, dentro desse quadro teórico que este trabalho pretende identificar e analisar as políticas públicas de extensão pesqueira artesanal, bem como analisar o capital humano dos pescadores da colônia Z-25, no município de Porto de Pedras, em Alagoas.

\section{CARACTERIZAÇÃO DA PESCA ARTESANAL NO MUNICÍPIO DE PORTO DE PEDRAS - ALAGOAS (2003 - 2009)}

A cidade de Porto de Pedras, segundo o Instituto Brasileiro de Geografia e Estatística (Ibge, 2007), foi elevada à categoria de município no ano de 1921, decorrente da lei número 903 . Esse município está situado nas coordenadas de Longitude 3529' Oeste e Latitude 9015' Sul, e enquadra-se na Microrregião Leste Alagoana e Mesorregião Leste Alagoana, possuindo a Mata Atlântica como bioma (Pnud, 2000). Ainda segundo o PNUD (2000), o município ocupa uma faixa territorial de $267,3 \mathrm{Km}^{2}$ e dista $74,2 \mathrm{Km}$ de Maceió, capital do Estado.

O município de Porto de Pedras, segundo os dados do Atlas do Desenvolvimento Humano, possui uma população aproximada de 10.238 pessoas, das quais $50,77 \%$ residem na zona urbana e $49,23 \%$ residem na zona rural. Quando comparamos os dados do PNUD (2000) relativos à população rural e urbana entre os anos de 1991 e 2000, percebe-se um crescimento de 8,80\% desta última. Logo, na última década, o percentual da população urbana era de $41,97 \%$ de pessoas. 
Vale salientar que a população de Porto de Pedras representa $0,36 \%$ da população do Estado de Alagoas (Pnud, 2000).

Com a relação aos indicadores educacionais da população adulta, ou seja, com 25 anos de idade ou mais, $71,7 \%$ possuem menos de quatro anos de estudo, $90,6 \%$ possuem menos de oito anos de estudo, e a média de anos de estudo é de 2,3 anos (Pnud, 2000).

Ainda segundo o PNUD (2000), o município de Porto de Pedras tem o Índice de Desenvolvimento Humano de 0,499 , considerada uma região de baixo desenvolvimento (IDH menor que 0,5).

Em relação a pesca artesanal, o município de Porto de Pedras caracteriza-se pela pesca extrativista de ambiente tanto estuarino quanto marítimo (IcmBio, 2008).

Ainda de acordo com Instituto Chico Mendes de Conservação da Biodiversidade (IcmBio, 2008), no município supracitado a produção de pescado no ano de 2006 foi de aproximadamente 125,40 toneladas, que representou $1,2 \%$ da produção do Estado de Alagoas, tendo um valor estimado de $\mathrm{R} \$ 481.128,7$ reais.

Desse total, 20,4 toneladas foram capturadas com a utilização de canoas e 90,1 toneladas com a utilização de jangadas.

O município de Porto de Pedras caracteriza-se por possuir cadastrados 11 canoas e 37 jangadas, totalizando 51 embarcações, que representam 1,9\% da frota pesqueira cadastra no Estado de Alagoas (IcmBio, 2008).

Especificamente em Porto de Pedras, os petrechos mais utilizados para a captura dos pescados no ano de 2006 foram: as redes de cerco e caceia, responsáveis por 27,9 e 77,4 toneladas, respectivamente, a linha de mão, 13,6 toneladas, e a tarrafa, com 5,3 toneladas, segundo dados do Instituto Chico Mendes de Conservação da Biodiversidade (IcmBio, 2008).

\section{POLÍticas públicas para a pesca ARTESANAL DE PORTO DE PEDRAS- ALAGOAS}

Após identificar as políticas públicas de extensão pesqueira para o desenvolvimento local do município de Porto de Pedras, entre 2003 e 2009, implementadas pelas organizações governamentais, verificou-se que duas instituições desenvolvem projetos tecnológicos ligados à pesca no referido município. São elas: Secretaria de Estado da Agricultura e do Desenvolvimento Agrário do Estado de Alagoas (SEAGRI) e Ministério da Pesca e Aquicultura (MPA).

\subsection{Projeto Ostreicultura em Porto de Pedras (SEAGRI-AL)}

O Projeto de Ostreicultura em Porto de Pedras teve início em janeiro de 2005 e é, de acordo com entrevista concedida para a pesquisa, pelo diretor de políticas pesqueiras do Estado de Alagoas, fruto da concepção e implantação da Secretaria de Estado da Agricultura e Desenvolvimento Agrário do Estado de Alagoas e da sua posterior parceria técnica com as seguintes organizações: Serviço Brasileiro de Apoio às Micro e Pequenas Empresas (SEBRAE), Instituto Ambiental Brasil Sustentável (IABS), Instituto do Meio Ambiente do Estado de Alagoas (IMA), Universidade Federal de Alagoas (UFAL) e a Agência Espanhola de Cooperação Internacional para o Desenvolvimento (AECID), que forneceu o apoio financeiro ao projeto. 
O objetivo do Projeto de Ostreicultura em Porto de Pedras é a consolidação de grupos de produtores de ostras no litoral norte de Alagoas, através do fomento da produção deste recurso, além da comercialização e agregação de valor ao produto, gerando uma atividade laboral e uma renda para os ostreicultores dos municípios envolvidos (Sebrae, 2010).

\subsection{Projeto Fábrica de Gelo (MPA)}

O Projeto da Fábrica de Gelo situa-se dentro do planejamento estratégico para o fortalecimento da cadeia produtiva do pescado proveniente da pesca artesanal da então Seap/PR, hoje MPA.

Para isso, foi estabelecida a meta de 120 comunidades pesqueiras, dentre as quais há a Colônia Z-25 do município de Porto de Pedras, contemplada no ano de 2006. Segundo entrevista concedida para esta pesquisa, o presidente da Colônia Z-25 informou ter submetido para apreciação governamental todos os documentos solicitados pelo edital 3/2009 da Secretaria Especial de Aquicultura e Pesca.

Esse projeto, segundo a Seap/PR (2009), foi fruto de um diagnóstico que identificou que parte da deficiência estrutural do setor pesqueiro artesanal deve-se à dificuldade desses pescadores artesanais em possuir meios de conservação do pescado e, fundamentalmente, o gelo.

Essa deficiência estimula a venda indireta do pescado, isto é, a venda para intermediários, acarretando apenas em uma pequena margem de lucro para os pescadores artesanais e aquicultores.

Assim, com esse projeto, o Governo Federal pretende garantir o acesso do setor pesqueiro artesanal e aquícola às políticas públicas de fortalecimento da cadeia produtiva, gerando renda e proporcionando uma melhoria da qualidade de vida dessas famílias.

\subsection{Projeto Caminhão Frigorífico (MPA)}

O projeto do caminhão frigorífico também está contemplado no planejamento estratégico para o fortalecimento da cadeia produtiva do pescado proveniente da pesca artesanal, do Ministério da Pesca e Aquicultura (MPA).

Para candidatar-se, a Colônia Z-25 protocolou, em 2009, na Superintendência Estadual do Ministério da Pesca de Alagoas, a documentação requerida no edital público, com o objetivo de desenvolver a pesca artesanal na comunidade.

Dessa forma, no ano de 2010, a Colônia foi contemplada com um veículo dotado com a capacidade de transporte de 1,5 toneladas de pescado, a ser cedido pelo MPA.

Segundo dados do Ministério da Pesca e Aquicultura (Brasil, 2010), esse projeto também foi fruto de um diagnóstico, o qual identificou que:

grande parte da deficiência estrutural do setor pesqueiro artesanal está vinculada às restrições de acesso aos meios de conservação do pescado [...]. Considera-se ainda a dificuldade de comercialização direta de produtos provenientes da pesca artesanal [...], pela ação de intermediários na cadeia produtiva [...] (Brasil, 2010, p. 1). 
Assim, com esse projeto, o Governo Federal também pretende garantir o acesso do setor pesqueiro artesanal e aquícola às políticas públicas de fortalecimento da cadeia produtiva, gerando renda e proporcionando uma melhoria da qualidade de vida dessas famílias (Brasil, 2010).

Apesar de a Colônia Z-25 ter sido contemplada na apreciação do MPA, no início do ano de 2010 o Governo esteve impedido de repassar à Colônia o veículo, em virtude das eleições para administração pública. Dessa forma, mesmo passadas as eleições, o projeto não foi implementado no município de Porto de Pedras. Isso se prende ao fato de o representante legal instituído pela Colônia Z-25 estar enfermo e, por essa razão, impossibilitado de dar continuidade a esse projeto.

\subsection{Projeto Cozinha Comunitária (MPA)}

O projeto da cozinha comunitária situa-se dentro do planejamento estratégico para o fortalecimento da cadeia produtiva do pescado proveniente da pesca artesanal, da então Seap/PR, hoje MPA.

Ainda de acordo com a Seap/PR (2008), esse projeto foi resultante do Plano Plurianual 2008-2011 do Governo Federal, que procurou estabelecer uma ação a fim de implantar uma infraestrutura aquícola e pesqueira, com a finalidade de gerar uma rede estratégica e regionalizada de infraestrutura para o desenvolvimento e o bom funcionamento integrado da cadeia produtiva aquícola e pesqueira.

Nesse projeto, vislumbraram-se os aspectos que incentivassem à organização, o associativismo e o cooperativismo, bem como o beneficiamento do pescado e sua posterior comercialização, observando aspectos como a qualidade, a segurança durante a manipulação do pescado, bem como a rentabilidade econômica e sustentabilidade ambiental da atividade (Seap/PR, 2008).

Visto que a Seap/PR (2008), embora reconheça que a pesca artesanal se destaca como uma atividade econômica com baixo grau de impacto ambiental, contrapõem a esse aspecto positivo seus processos produtivos. Isto é, a falta de acesso aos meios de produção, a dependência das formas predominantes de comercialização do pescado (venda a atravessadores), a melhoria da qualidade do pescado a ser comercializado, assim como o não beneficiamento que agregaria valor ao produto final.

Dessa forma, o Governo Federal pretendeu com esse projeto desenvolver empreendimentos voltados ao setor pesqueiro artesanal, a fim de solucionar ou minimizar os problemas supracitados. Com isso, pretendeu garantir o acesso do setor às políticas públicas de fortalecimento da cadeia produtiva, gerando renda e proporcionando uma melhoria da qualidade das comunidades pesqueiras.

\section{CAPITAL HUMANO PARA O DESENVOLVIMENTO LOCAL DA PESCA ARTESANAL EM PORTO DE PEDRAS}

Como observado anteriormente, o capital humano fortalecido surge a partir de investimentos na educação e treinamento do indivíduo (Moretto, 1997).

Considera-se novamente que esse capital humano se fortalece na medida em que as pessoas possuam habilidades, competências e que tenham educação e motivação a fim de 
conduzir processos de mudanças. Buscando, assim, alcançar uma sociedade sustentável (Jara, 2001).

Dentro dessa perspectiva, os pescadores associados à Colônia Z-25 deveriam ser capazes de influenciar as ações desta instituição, através de sua participação na colônia.

Esta participação implicaria que os debates acerca do funcionamento institucional da Z-25 e sua forma de atuação junto às entidades governamentais proporcionassem aos membros diretores dessa organização um apoio no processo de suas ações. Além disso, os debates sobre as políticas públicas para a pesca artesanal em Porto de Pedras, a manutenção dos projetos existentes e as eventuais proposições nos projetos governamentais vindouros, fariam com que estas ações se aproximassem cada vez mais das demandas locais.

Considerando a importância do capital humano, tanto do ponto de vista dos pesquisadores do assunto, quanto pelo próprio reconhecimento do Estado, por meio da ATEPA, em se fomentar esse capital na pesca artesanal, observou-se que, na realidade do município de Porto de Pedras, os investimentos em capital humano são incipientes.

Sendo assim, o projeto desenvolvido pela Secretaria de Agricultura e do Desenvolvimento Agrário do Estado de Alagoas, embora utilizasse recursos para fomentar aspectos do capital humano, como por exemplo, oficinas em associativismo, cooperativismo e gestão de pequenos negócios, esses eventos parecem que se restringiram a atender apenas a perspectiva de administração empresarial. Sobre isso, o presidente da Colônia Z-25, diz que o SEBRAE se limitou a promover tais eventos com vistas ao agronegócio:

Você sabe que o SEBRAE tem uma visão de formar e incentivar as pequenas empresas, e foi isso que ele quis fazer aqui com esses cursos. Por mim, esses cursos de associativismo seriam voltados para conscientizar politicamente os associados da Colônia, para eles saberem se organizar para poder reivindicar seus direitos. Eu mesmo fui líder sindical quando era funcionário da Companhia Energética de Alagoas e sei o quanto é importante uma associação forte (Presidente da Colônia Z-25).

Dessa maneira, consideramos que essas ações (cursos, oficinas, palestras) foram insuficientes para fortalecer o capital humano da Colônia e, por conseguinte, insuficiente para auxiliar na implantação de processos de desenvolvimento local.

Essa insuficiência e ineficácia nos projetos de fomento do capital humano para a pesca artesanal também existiram nos projetos desenvolvidos pela então Secretaria Especial de Aquicultura e Pesca da Presidência da República (Seap/PR).

No projeto de implantação de fábricas de gelo, o fomento ao capital humano foi apenas vislumbrado nos treinamentos sobre operacionalização e manutenção de fábricas de gelo, boas práticas de fabricação de gelo e segurança do trabalho.

Ainda no que se refere ao fomento do capital humano nesse projeto, como pontuado anteriormente, além de ter havido uma capacitação limitada de pescadores para atuarem nessas fábricas de gelo, observou-se também que no Programa Nacional de Capacitação para a Autogestão das Fábricas de Gelo, os cursos sobre associativismo e cooperativismo autogestionário, planejamento estratégico, identificação de custos e organização financeira e de técnicas de vendas, tiveram um enfoque meramente empresarial (Seap/PR, 2009). 
A propensão do Ministério da Pesca e Aquicultura ao desenvolver o projeto de fábrica de gelo para a gestão de negócio também pôde ser observada através dos objetivos específicos desse projeto, quando se refere à melhoria da qualidade da cadeia produtiva do pescado, à disponibilização de equipamentos de fabricação de gelo de fácil instalação, com menor custo operacional possível e o desenvolvimento de um programa de capacitação para apoiar a autogestão das fábricas de gelo (Mpa, 2011).

Nessa perspectiva, há de se inferir que a implementação desse projeto na Colônia Z-25 de Porto de Pedras não contribuiu efetivamente para o fortalecimento do capital humano, mas apenas um fomento pontual deste capital, com vistas à operacionalização das máquinas e da venda do produto, neste caso o gelo. Logo, o projeto de capacitação de pescadores para atuarem nas fábricas de gelo está distante do entendimento considerado nesta pesquisa de como o capital humano deve ser considerado e trabalhado, isto é, com vistas ao desenvolvimento local. Como se refere Jara (2001, p.100), "A construção de sociedades sustentáveis e do desenvolvimento local depende de sólido empreendimento em capital humano [...]".

O segundo projeto implantado pela Secretaria Especial de Aquicultura e Pesca (Seap/PR) no município de Porto de Pedras - Alagoas, que visa ao uso de tecnologias para o desenvolvimento local por meio da pesca artesanal, é a utilização do caminhão frigorífico.

Embora nesse projeto não houvesse a necessidade de capacitação técnica dos pescadores, foi instituído um contrato coletivo entre os associados da Colônia Z-25 no sentido de que o caminhão frigorífico (nesta pesquisa, considerado como um recurso tecnológico) pudesse ser um meio para a conservação do pescado, facilitando assim o escoamento da produção pesqueira local, in natura ou eventualmente beneficiado, para novos mercados consumidores, permitindo assim o surgimento de novas formas de produção e de comercialização do pescado.

A implantação da cozinha comunitária é outro projeto identificado para a Colônia Z-25 de Porto de Pedras, que visou fortalecer a cadeia produtiva do pescado proveniente da pesca artesanal. Para isso, segundo entrevista realizada para esta pesquisa, o presidente da Colônia Z-25 informou que o SEBRAE promoveu uma capacitação de 15 pescadoras, por meio de cursos sobre associativismo, cooperativismo, beneficiamento e comercialização do pescado, qualidade e segurança na manipulação do produto, rentabilidade econômica do beneficiamento do pescado.

Ainda no que se refere ao projeto de implantação da cozinha comunitária, observou-se que os cursos realizados tiveram um interesse mais voltado ao fomento do capital humano para a atividade empresarial, tal como observamos em relação à fábrica de gelo.

Segundo relato de uma pescadora, que informou ter participado da capacitação, os participantes do projeto supracitado tiveram oficinas sobre extração do couro e filé do pescado, além de aulas sobre estratégias de venda e higiene. Ainda segundo a entrevistada, as aulas sobre associativismo eram trabalhadas na perspectiva empresarial, considerando que "[...] quando os funcionários do governo estiveram por aqui, falaram que a gente iria fazer um curso para vender o filé e o couro do peixe, e que nossa renda aumentaria no final do mês, porque a gente iria aprender a vender o pescado" (Pescadora associada à Colônia Z-25).

Dessa forma, observamos que tanto a Seap/PR quanto a SEAGRI não buscaram abordar o associativismo como uma ferramenta também importante para o desenvolvimento da Colônia Z25 , no sentido de estreitar os laços entre a sociedade organizada e o poder público, mediante uma 
maior participação, vista neste trabalho como o compartilhamento do poder nas tomadas de decisões (Peruzzo, 1998) pelos pescadores artesanais nos debates acerca das políticas públicas para a atividade pesqueira e de preservação ambiental.

Essa forma de implementar os projetos na Colônia Z-25 permite inferir que o fomento do capital humano na pesca de Porto de Pedras tem sido visto, pelas organizações, apenas como um complemento aos projetos ora analisados. Cumprindo, assim, apenas um requisito mínimo para a execução dessas políticas públicas extensionistas. Tal aspecto revela o quanto as diretrizes do Plano Nacional de Assistência Técnica e Extensão Rural (PNATER), da ATEPA, bem como, o cumprimento do regimento interno da Seap/PR não estão sendo atendidos na sua plenitude.

A valorização do capital humano deveria ser estimulada e incorporada cada vez mais nos projetos para o desenvolvimento local, pois, segundo Moretto (1997), a partir da ampliação do capital humano é possível não só aumentar a produtividade desse trabalhador, mas também é possível reduzir a pobreza, redistribuir a renda e, consequentemente, estabelecer na sociedade uma equidade cultural e socioeconômica.

Como já analisado, os projetos para a Colônia Z-25 de Porto de Pedras ainda são escassos e/ou incipientes para que possam gerar um desenvolvimento local auto-suficiente na comunidade. Ao lado disso, soma-se o baixo investimento no capital humano da pesca artesanal desse município, ainda que previsto na metodologia da ATEPA.

Se inferimos que as políticas públicas para o desenvolvimento local da pesca artesanal não contemplam o capital humano, poderão ser insuficientes, como historicamente já foi observado neste trabalho, para a transformação da realidade socioeconômica de uma comunidade pesqueira. Corroboramos, então, com o argumento de Jara (2001) quando defende um fomento sistemático do capital humano, com a finalidade de promover o desenvolvimento local.

Nesse sentido, os aspectos até aqui analisados sinalizam para a necessidade atual de se investir no capital humano, nos projetos para o desenvolvimento da pesca artesanal de Porto de Pedras, para além de uma perspectiva empresarial. Segundo Pires $(2005$, p. 3), o investimento nesse capital está "na ordem do dia das políticas públicas governamentais e das recomendações [...], de organismos financeiros multilaterais e não financeiros". Jara (1998) afirma também que para se pensar o desenvolvimento local deve-se partir da valorização do capital humano.

\section{CONCLUSÕES}

Os projetos aqui analisados tiveram dois objetivos distintos. O desenvolvido pela SEAGRIAL buscou consolidar grupos de produtores de ostras em Porto de Pedras, através do fomento à produção e comercialização deste recurso, na perspectiva de gerar uma atividade laboral e uma renda para os ostreicultores do município (Sebrae, 2010). Já os projetos desenvolvidos pelo MPA foram traçados dentro do planejamento estratégico que visava fortalecer a cadeia produtiva do pescado proveniente da pesca artesanal. Vimos que apenas dois projetos foram implementados na sua integralidade. A outra metade foi executada apenas em parte.

Ainda no que se refere a esses projetos integralmente implementados, os quais vislumbravam o desenvolvimento da pesca artesanal em Porto de Pedras, salientamos, contudo, que seus objetivos não foram assegurados por inteiro. $O$ que se propunha à produção de ostras teve uma desistência de $50 \%$ de seus integrantes iniciais. Atualmente este projeto encontra-se 
com uma redução gradual de suas atividades. Esse insucesso deveu-se, inicialmente, à utilização de petrechos ultrapassados (camas de madeira) que possuem uma vida útil reduzida quando comparada com os equipamentos mais modernos (PVC), bem como requerem uma manutenção periódica constante.

Esse fator contribuiu para uma perda produtiva gradativa, gerando uma diminuição da renda obtida com a ostreicultura e, até mesmo, uma incerteza por parte desses trabalhadores quanto à viabilidade do projeto.

O segundo projeto integralmente executado tratou da implementação de uma fábrica de gelo. Este projeto, na avaliação desta pesquisa, também não produziu os efeitos esperados. Sua finalidade seria o fortalecimento da cadeia produtiva da pesca artesanal. Parte desse malogro resultou da venda de quase toda a totalidade do gelo produzido para o comércio local, assim como pela falta de capital financeiro dos pescadores associados à Colônia Z-25 para adquirirem este insumo, utilizado para a conservação do pescado. Isso fez com que os pescadores artesanais continuassem vinculados aos atravessadores, visto que também têm a necessidade de se desfazerem do pescado capturado rapidamente, dada as características de perecibilidade dos animais aquáticos.

Sob o ponto de vista do capital humano para o desenvolvimento local, observou-se que o insucesso desses projetos foi detectado quando os agentes públicos relegaram o fomento a essa dimensão do desenvolvimento local apenas como meio ou forma para se conseguir implementar os projetos. Assim, o capital humano foi fomentado mediante a oferta de oficinas, palestras e cursos, desconsiderando a baixa escolaridade dos pescadores artesanais da Colônia Z-25 de Porto de Pedras, bem como se esse indicador (baixa escolaridade) contribuía para o não empoderamento dos atores sociais, portanto dificultando o estabelecimento de instruções que visassem ao desenvolvimento local.

Ao considerarmos as observações de Jara (2001), quando afirma que se deve trabalhar o capital humano na perspectiva do desenvolvimento local, neste caso dos pescadores artesanais, como agentes de desenvolvimento, este estudo revelou que as políticas públicas para o desenvolvimento de Porto de Pedras desconsiderou esse aspecto fundamental para dinamizar os processos em prol do desenvolvimento local de uma região. Nesse sentido, os pescadores não tomaram para si estes projetos. Isto é, não se viram como agentes autônomos, mas quase sempre passivos às orientações dos órgãos públicos. Além disso, outro aspecto relacionado ao fracasso dos projetos foi o fato de as instituições públicas não terem atendido previamente a comunidade pesqueira de Porto de Pedras, em seus interesses mais elementares. Segundo relatado por alguns dos entrevistados desta pesquisa, esses investimentos básicos não estavam relacionados a investimentos em implantação de fábrica de gelo tampouco por uma implantação de uma unidade de produção de ostras, como a realizada pela SEAGRI - AL, mas mencionaram, por exemplo, a introdução de projetos com vistas à educação e capacitação dos pescadores e seus filhos.

Os relatos analisados após as entrevistas também vieram a afirmar que todos os projetos voltados à pesca artesanal, implantados no espaço temporal compreendido entre os anos 2003 a 2009, em Porto de Pedras, não lograram os resultados esperados pelos próprios associados à Colônia Z-25.

Quando se analisou as políticas públicas extensionistas aplicadas para o citado município, observou-se que o estímulo tanto ao emponderamento dos pescadores e pescadoras, quanto ao 
desenvolvimento do capital humano, como dimensão importante para instaurar processos de desenvolvimento local através dos projetos implantados, foi, ao que tudo indica, rudimentar. Identificou-se também que as políticas públicas analisadas ainda demonstraram verticalidade na elaboração e execução dos projetos.

Deve-se salientar, entretanto, que os investimentos realizados no capital humano da Colônia de Pescadores Z-25, em Porto de Pedras, no decurso dos projetos da fábrica de gelo e do cultivo de ostras, tiveram sua importância na medida em que permitiram que alguns associados adquirissem informações para a operação com segurança da fábrica de gelo, noções de cultivo de ostras e de associativismo.

Em síntese, ao se constatarem lacunas nos projetos sob o ponto de vista do investimento no capital humano, e considerando a proposição de Franco (2000) de que só atingimos o desenvolvimento quando se contempla também o aspecto humano, vimos que faltam componentes institucionais ou normas objetivas nos projetos para a construção desse capital humano para o desenvolvimento local em Porto de Pedras.

Essa característica da Colônia Z-25 de possuir em sua organização um frágil capital humano nos permite concluir que este seja um dos pontos que entravam o desenvolvimento local do município por meio da atividade pesqueira artesanal.

Assim, é de fundamental importância que os pescadores de Porto de Pedras sejam estimulados a se emponderarem para que possam identificar, avaliar e equacionar suas dificuldades com autonomia decisória, com adequação e eficácia, conforme defende Jara (2001).

Para isso, sugerimos que o Ministério da Pesca e Aquicultura (MPA), devidamente assessorado pelas Superintendências Federais de Pesca e Aquicultura, estabeleça uma parceria com o Ministério da Educação (MEC), através de instituições públicas de ensino, pesquisa e extensão, a fim de oferecerem em conjunto cursos de educação formal específicos para os pescadores dos diferentes locais da federação que desenvolvam a pesca artesanal. Assim, ao instaurar políticas públicas complexas como a sugerida acima, será construído e/ou aperfeiçoado o capital humano para o desenvolvimento local nas Colônias de Pescadores contempladas com essas medidas. Ou seja, fazendo com que este capital humano busque, através de seu potencial endógeno, a melhoria local da saúde, educação, geração de trabalho e renda, tendo para isso a sustentabilidade como parâmetro.

Assim, ao se combater inicialmente a fragilidade da Colônia Z-25, caracterizada pela precariedade de seu capital humano, torna possível a efetivação de seu desenvolvimento local, condição ainda não observada nos projetos realizados em Porto de Pedras.

Deve-se mencionar também que um entrave para o desenvolvimento local da pesca artesanal em Porto de Pedras é o emprego de tecnologias defasadas na pesca na região. Todavia, aspectos de ordem política local, o não estabelecimento de parcerias entre as instituições públicas de ensino, pesquisa e extensão e as Colônias de Pescadores, o não financiamento público na manutenção dos projetos relacionados à atividade pesqueira artesanal, debilitam esta cadeia produtiva. Isso irá gerar dificuldades de inserção dos produtos lá produzidos no mercado de consumo.

Com essa realidade socioeconômica, a não implementação de políticas públicas para o desenvolvimento local da pesca artesanal com vista à construção de um capital humano 
emponderado, a Colônia Z-25 de Porto de Pedras se manterá como uma localidade possuidora de um potencial endógeno (meio ambiente e pessoal) que favorece a atividade pesqueira artesanal, sem, no entanto, conseguir traduzir isso em riqueza social, econômica e cultural para esses pescadores.

\section{REFERÊNCIAS BIBLIOGRÁFICAS}

1. BRASIL. Lei Delegada no.10 de 11 de outubro de 1962. Cria a Superintendência do Desenvolvimento da pesca e dá outras providências. In: Diário Oficial da União, Brasília,DF,11 out. 1962. Disponível em: <http://www3.dataprev.gov. br/sislex /paginas/ 41/1962/10.htm>. Acesso em: 27 mai.2010.

2. BRASIL. Ministério do Desenvolvimento Agrário. Política nacional de assistência técnica e extensão rural. Brasília:MDA/SAF/DATER,2004.

3. BRASIL. Secretaria Especial de Aquicultura e Pesca. Plano Nacional de Extensão Pesqueira e Aquícola. Brasília: Seap/PR, 2007.

4. BRASIL. Ministério da Pesca e Aquicultura. Edital Público 12/2010. In: Diário Oficial da União, Brasília, DF, 31 ago. 2010. Disponível em: <http://www.mpa.gov.br>. Acesso em: 15 nov. 2010.

5. BRASIL. Ministério da Pesca e Aquicultura. Balanço das Políticas e programas de governo voltados para o desenvolvimento sustentável da pesca e da aquicultura 2003-2010. Brasília: MPA, 2011. (Documento de circulação restrita).

6. CALLOU, Angelo Brás Fernandes. Movimentos sociais de pescadores em Pernambuco (19201983). Santa Maria: UFSM, 1986. Dissertação de mestrado apresentada no Programa de PósGraduação em Extensão Rural, da Universidade Federal de Santa Maria.

7. CALLOU, Angelo Brás Fernandes. A voz do mar, construção simbólica da realidade dos pescadores brasileiros pela missão do cruzador "José Bonifácio" (1919-1924). 1994. 74p. Tese (doutorado em Ciências da Comunicação) - Escola de Comunicação e Artes da Universidade de São Paulo. São Paulo,1994.

8. CALLOU, Angelo Brás Fernandes. O Associativismo pesqueiro no Brasil: aspectos históricos e perspectivas. Série Documento,UFRPE - Departamento de Educação - PAPE, 1995.

9. CALLOU, Angelo Brás Fernandes; TAUK SANTOS, Maria Salett. Formação de comunicadores rurais: novas estratégias para enfrentar o século XXI. Contexto e Educação, Ijuí, Unijuí, n.63,jul.set.,2001.p.119-130.

10. CALLOU, Angelo Brás Fernandes; TAUK SANTOS, Maria Salett. A extensão pesqueira e gestão no desenvolvimento local. In: Extensão Pesqueira: desafios contemporâneos. Recife: Bagaço, 2003.p.223-236.

11. CARVALHO, Felipe Eduardo Araújo de. Extensão pesqueira e desenvolvimento local: a experiência da secretaria especial de aquicultura e pesca no estado de Pernambuco, 20032006. Recife: UFRPE, 2007. 78 p. Dissertação de mestrado apresentada no Programa de PósGraduação em Extensão Rural e Desenvolvimento Local (POSMEX), da Universidade Federal Rural de Pernambuco.

12. CASADINHO. Projeto pescando pescadores: Políticas Públicas e Extensão Pesqueira para o 
Desenvolvimento Local. Recife (PE): 2006.

13. CUNHA, Elton José da. Políticas públicas e capital social para o desenvolvimento local da pesca e da aquicultura no Vale do Piancó - Paraíba (2003 - 2007). Recife: UFRPE, 2009. 81 p. Dissertação de mestrado apresentada no Programa de Pós-Graduação em Extensão Rural e Desenvolvimento Local (POSMEX), da Universidade Federal Rural de Pernambuco.

14. DIEGUES, Antonio Carlos Sant'Ana. Pescadores, camponeses e trabalhadores do mar. São Paulo: Ática, 1983. 287p.

15. DIEGUES, Antonio Carlos Sant'Ana. Os pescadores artesanais e a questão ambiental. In: Povos e mares: leituras em sócio-antropologia marítima. São Paulo: NUPAUB-USP. 1995. p. 131-138. (a).

16. DIEGUES, Antonio Carlos Sant'Ana. Povos e mares: uma retrospectiva de sócio-antropologia marítima. In: Povos e mares: leituras em sócio-antropologia marítima. São Paulo: NUPAUBUSP. 1995. p. 01-26. (b)

17. FRANCO, Augusto de. Porque precisamos de desenvolvimento local integrado e sustentável. 2. ed. Brasília, DF, Millennium, 2000.

18. Instituto Brasileiro de Geografia e Estatística - IBGE. 2007. Histórico de Porto de Pedras. Disponível em:<http://www.ibge.gov.br/cidadesat/painel/painel.php?codmun=27 0740 >. Acesso em $11 \mathrm{dez} .2010$.

19. Instituto Chico Mendes de Conservação da Biodiversidade - ICMBio. Projeto ESTATPESCA Monitoramento da Atividade Pesqueira no Litoral Nordestino. Tamandaré-PE, 2008. 385p.

20. JARA, Carlos Julio. A sustentabilidade do desenvolvimento local: desafios de um processo em construção. Brasília: Instituto Interamericano de Cooperação para a Agricultura (IICA): Recife: Secretaria do Planejamento do Estado de Pernambuco - Seplan, 1998. 316p.

21. JARA, Carlos Julio. As dimensões intangíveis do desenvolvimento sustentável. Expo Brasil Desenvolvimento Local. IICA - Brasil. Brasília: 2001.(Colaboração de Maria Verônica Morais Souto).

22. JESUS, Paulo de. Desenvolvimento local. In: A outra economia. CATTANI, Antonio David (org). Porto Alegre: Veraz Editores, 2003.

23. MATTOS, Solange Maria da Silva Nunes; DRUMMOND, José Augusto. O terceiro setor como executor de políticas públicas: Ongs ambientalistas na baía de Guanabara (1990-2001). Rev. Sociol. Polit., Curitiba,n. 24, jun. 2005. Disponível em < http://www.scielo.br/scielo.php?script=sci_arttext\&pid=S010444782005000100012\&lng=pt \&nrm=iso>. Acesso em 12 abr. 2010. doi:10.1590/S0104-44782005000100012.

24. MORETTO, Cleide Fátima. O capital humano e a ciência econômica: algumas considerações. Passo Fundo: v.5, no 9, maio. 1997, p.67-80.

25. PERUZZO, Maria Cicilia Krholing. Comunicação nos movimentos populares: a participação na construção da cidadania. Petrópolis: Vozes, 1998. p.73-88.

26. PIRES, Valdemir. Economia da educação: para além do capital humano. São Paulo: Cortez, 2005.142p.

27. Programa das Nações Unidas para o Desenvolvimento - PNUD. Atlas do Desenvolvimento Humano no Brasil. [2000]. Disponível em <http://www.pnud.org.br/atla 
s/>. Acesso em 15 Jan 2010.

28. SARAIVA, Rosa Maria. Políticas Públicas e extensão rural para o desenvolvimento local: estudo das estratégias de comunicação dos projetos Renascer e PROMATA nas comunidades de Atapuz, Barra de Catuama e Tejucupapo, Goiana-PE. Dissertação de mestrado apresentada no Programa de Pós-Graduação em Extensão Rural e Desenvolvimento Local (POSMEX), da Universidade Federal Rural de Pernambuco.

29. Secretaria Especial de Aquicultura e Pesca - Seap/PR. Edital Público 002/2008. In: Diário Oficial da União, Brasília,DF, outubro 2008. Disponível em: <http://ww w.mpa.gov.br >. Acesso em: 14 nov.2010.

30. Secretaria Especial de Aquicultura e Pesca - Seap/PR. Edital Público 003/2009. In: Diário Oficial da União, Brasília,DF,18 maio 2009. Disponível em: <http://www. mpa.gov.br >. Acesso em: 15 nov.2010.

31. Serviço Brasileiro de Apoio às Micro e Pequenas Empresas - SEBRAE. Projeto de Ostreicultura na Região do Litoral de Alagoas. Maceió-AL, 2010. 3p.

32. SIRY, Bernardo. Experiências pastorais no meio dos pescadores artesanais. In: Extensão Pesqueira: desafios contemporâneos. Recife: Bagaço, 2003.p.27-42.

33. TAUK-SANTOS, Maria S.; CALLOU, Angelo B. F. Desafios da comunicação rural em tempo de desenvolvimento local. In: Signo, João Pessoa, Ano 2, n0.03, set. 1995, p.42-47.

34. TAUK-SANTOS, Maria Salet. Comunicação Rural - velho objeto, nova abordagem: mediação, reconversão cultural, desenvolvimento local. In: LOPES, Maria Immacolata Vassalo de; FRAUMEIGS, Divina; TAUK-SANTOS, Maria Salett (Org.). Comunicação e informação: identidades e fronteiras. São Paulo / Recife: Bagaço, 2000. p.291-301.

35. TAUK-SANTOS, Maria Salet; SPENILLO, Giuseppa. Uma nova política para o ensino da comunicação rural: o caso da UFRPE. In: TAUK-SANTOS, Maria Salett (Org.). Políticas de comunicação rural nos anos 90. Recife: UFRPE / Imprensa Universitária, 1997. p.111-127.

36. TEIXEIRA, Elenaldo Celso. As dimensões da participação cidadã. Cad. CRH, (UFBA), Salvador, v. 26/27, p.179-209, jan./set.1997.

37. TEIXEIRA, Elenaldo Celso. O papel das políticas públicas no desenvolvimento local e na transformação da realidade. Associação dos Advogados de Trabalhadores Rurais (AATR-BA), Salvador, 2002. 